\title{
Problems of human resources modernization and the formation of a proposal labor force in the youth labor market
}

\author{
Tatyana Petrenko*, Irina Marinova, Alexander Zimovets, and Liliya Leonova \\ Taganrog Management and Economics Institute, Taganrog, Russia
}

\begin{abstract}
The labor market in the modern economic system is the most dynamically changing sphere of the economy, where all new trends demonstrate characteristics corresponding to the realities of the modernizing world, which make it possible to judge the directions of such modernization. Changes in the qualitative requirements for human resources, the instability of the market environment and increased mobility of all market segments, especially against the background of the influence of lockdowns on various aspects of society, presupposes the actualization of the solution to the problems of human resources modernization. This is especially important for expanding the potential of the labor force through the most dynamic and mobile part of it - the youth labor market. The expansion of formalized requirements for the professional and qualification characteristics of workers determines the directions of the labor market. Traditional vocational guidance cannot be viewed as an argument that allows one to form appropriate perceptions and opportunities for quality choices. There is a need for new institutional forms of organizing the interaction of all stakeholders - employers studying in educational institutions of various levels of training, professional educational organizations, regional employment centers, recruiting agencies, for example, youth library and information centers, whose functions include information, educational, cultural, technological areas of work.
\end{abstract}

Human resources in the modern economic system in the process of accumulating innovative potential, its application and, associated with this, transformations in the development of productive forces, are faced with significant changes in the requirements that the objectively changing world imposes on them. Structural shifts determine the growth of the level of demand for appropriate personnel capable of adequately responding to the demands of the time, generating the necessary results for the purpose of dynamic growth and development. This leads to shifts in all types of industrial relations and is manifested, first of all, in the functioning of the labor market, which is a dynamic system of relations built on the interaction of employers and employees with the participation of state and

\footnotetext{
${ }^{*}$ Corresponding author: t.petrenko@tmei.ru
} 
public organizations that determine the ratio of supply and demand for labor for different market segments.

The issues of qualitative transformations of human resources in the context of information development are highly relevant and are reflected in various publications $[1,2,3]$. The information society seems to be the most dynamic system that requires an appropriate quality of economic resources, including labor, considering the peculiarities of the regional level of socio-economic development and the aggravating problem of multistructure [4]. Information and its transmission channels are of decisive importance here. The compliance of the information field with the requirements of the system, its potential and growth is one of the priority conditions for sustainable development. In the context of determining the requirements for human resources, considerable attention is paid to the analysis of the relevant competencies, both in terms of their definition [1] and formalization through the system of professional standards, created on the basis of the National Qualifications Framework [5,6]. Changes in the quality requirements for human resources most significantly affect the youth labor market. A similar market, covering both those who have already merged into market relations, having a certain professional and qualification level and trying to find an application for their capabilities, based on the prevailing realities, including those associated with the problem of lockdowns, and those who are just at the stage of the upcoming professional choice $[7,8,9]$.

New requirements for human resources in the modern labor market determine new approaches to the analysis of the mechanisms of its development, as well as institutional forms of organization, the study of which is an urgent task of modern economic science and practice. The main goal of the work on organizing the interaction of potential employees and employers at various levels is to harmonize the market situation so that the prerequisites for a stable balance are formed. However, the transformational processes that modernize the production system itself also determine the trends towards imbalance in markets. One of the mechanisms allowing to improve the work on harmonization of requirements for the workforce and its real quality is seen as the institution of social partnership, which provides opportunities for harmonizing the interests of stakeholders so that representatives of the real economy, the educational sector and public administration can effectively and purposefully coordinate their requirements and capabilities. There are some interests here. Firstly, to analyze the specifics of the conjuncture of regional labor markets, which require not so much a statement of the prevailing realities as predictive modeling of the conditions for the development of these markets. Secondly, the formation of information channels for broadcasting to interested relevant information about the specifics of the situation, forecasts of its possible changes, as well as the existing regulatory and legal conditions, considering the national legislative framework.

Research issues on the regional labor market are often associated with the activities of employment centers and various recruitment agencies, which, to a greater or lesser extent, identify and describe the current situation on the market, organize vocational guidance, retraining, promote employment, etc. However, this activity, which is indisputably important and in demand, does not form that adaptive potential, considering the prevailing realities, which can ensure economic growth and development. For the domestic economy, this is all the more important due to significant differences in the levels of development of individual territories, which actualizes the need for a deeper and more qualitative analysis of regional labor markets. Monitoring of this market can be aimed at this, the functions of which, traditionally, include the formation of an information base to ensure measures to improve the situation, develop recommendations for economic policy in the field of employment, prepare programs for coordinating measures aimed at reducing tension in the labor market in the region and etc. [10]. So, for example, in the city of Taganrog, since 2010, the municipal monitoring of the city's labor market has been carried out within the 
framework of the tripartite agreement of the Taganrog Management and Economics Institute, the City Administration and the Employment Center. It is organized considering the needs of enterprises and organizations of Taganrog in qualified labor resources of various professional qualification groups and is focused on solving a number of problems. First of all, this is a study and reflection of the phenomena and processes taking place in the city that affect the formation of the local labor market. Further - this is the provision of operational information management bodies and high-quality analytics, which allows, on the basis of the data received, to formulate conclusions, both about the current state of affairs, and, considering the opinions of various specialists involved in the study, to draw up a more realistic picture of the object in question. Such an approach makes it possible to more reasonably substantiate a set of measures for organizing and regulating labor relations in the city, in particular in the field of planning and introducing data on the state of the labor market and forecasts for changes in its conjuncture into the vocational guidance system [10]. The study of the labor market, which is carried out regularly over a fairly long period, makes it possible to formulate recommendations for adjusting the Program of interaction between labor markets and educational services at the regional level to reduce tensions. The main results are recorded in analytical notes and widely published in various sources.

So, as in 2018-2019 a study was carried out of 87 organizations of the city of various organizational and legal forms. As a result, along with data on the average number of employees, their gender and age characteristics (considering the separation of preretirement and retirement ages, as well as disability), distribution by education levels, pay, incentive payments, etc., various programs to stimulate the development of personnel were investigated. The analysis of the criteria on which employers are most oriented in the process of selecting personnel for prospective vacancies is enough interesting.

The level of qualifications, education and work experience, as the most significant, from the point of view of employers, were ranked, and the ranks were presented as follows - the most preferred had the lowest rank. The results obtained in dynamics are presented in Figure 1.

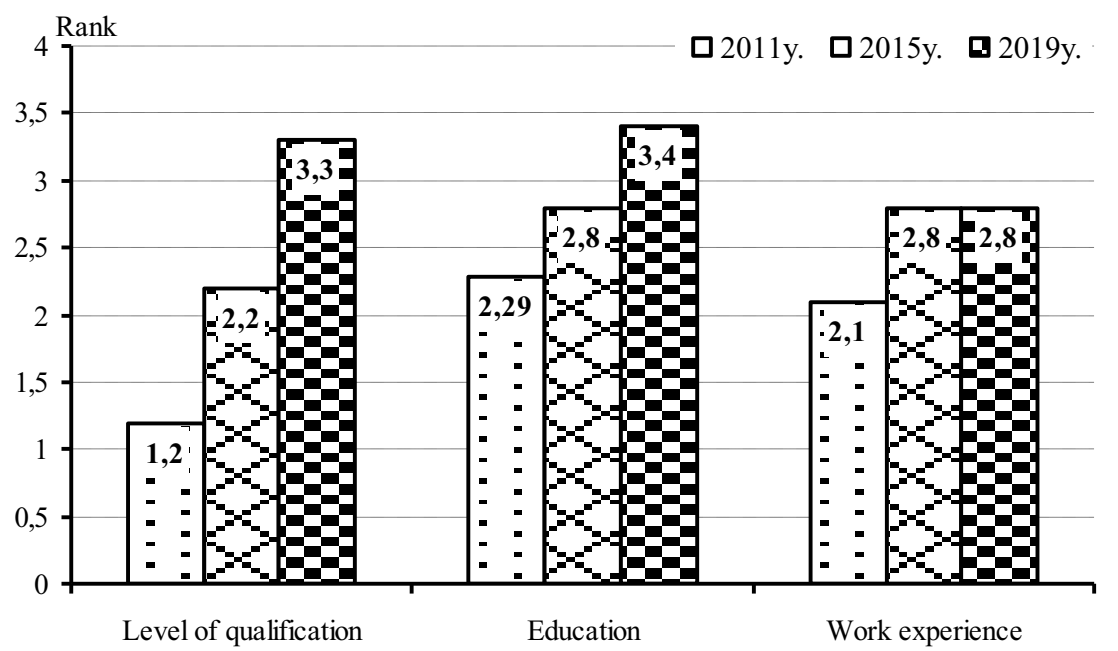

Fig. 1. Criteria for the importance of various characteristics when applying for a job

In world practice, the development of labor skills together with the growth of knowledge, improvement and retraining are attributed to the increasingly widespread educational model of Life Long Learning [11]. It is most clearly illustrated by the example 
of the Danish experience of organizing the labor market, which combines flexibility and security with an active government policy on the labor market. This model is built on flexible hiring and firing rules that allow employers to lay off employees during an economic downturn and hire new ones when the situation improves, and such mobility is focused on the flexicurity recipe [12]. It is about stimulating and dynamizing employment, which implies a continuous mechanism for obtaining education, retraining and retraining an employee throughout his working life. At the same time, the system itself harmonizes the desire of people to develop and try themselves in various segments of the labor market, creating conditions for reducing, for example, monopsony pressure on the market. About a quarter of those employed in the Danish private sector change jobs every year. This flexibility is combined with unemployment insurance, which guarantees relatively high unemployment benefits - up to $90 \%$ for the lowest paid workers. Conducting an active policy on the labor market makes it possible to create an effective system of career guidance, training and, ideally, employment of all unemployed people in the country. At the same time, about $1.5 \%$ of Denmark's GDP is allocated to finance an active policy on the Danish labor market [13].

At the same time, characterizing preferences in terms of the level and nature of education, the following features were revealed (Fig. 2).

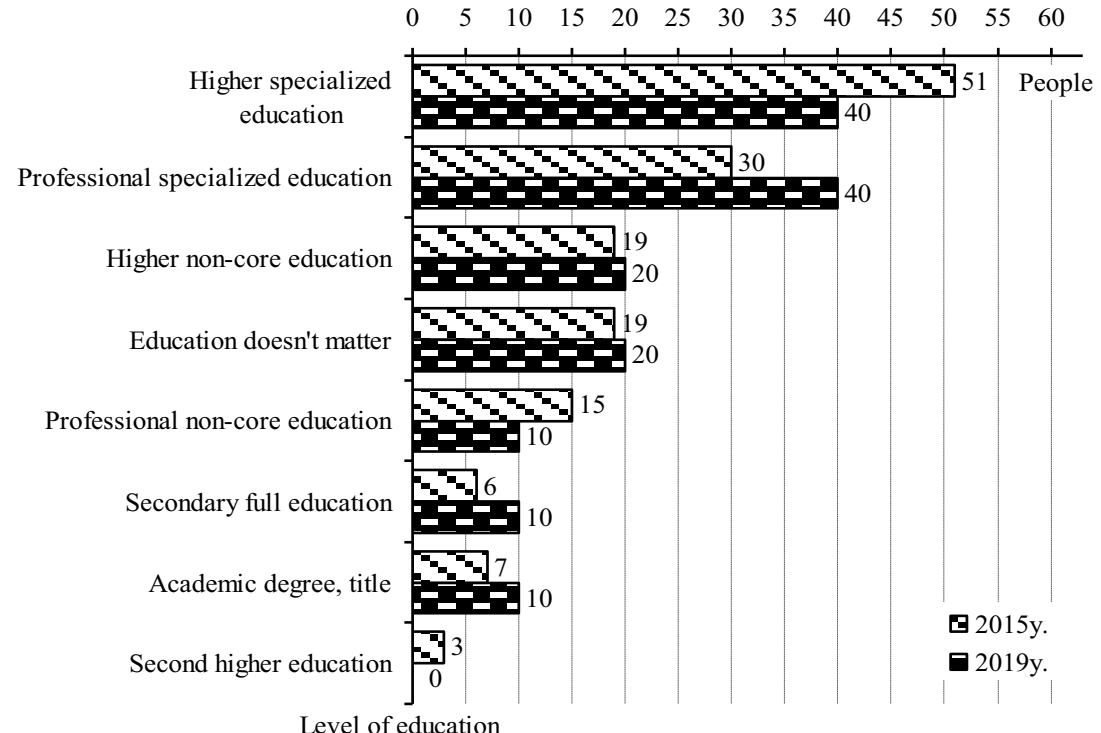

Fig. 2. Preferences in terms of the level and type of education.

The leading position is occupied by higher and professional specialized education. Interest in specialists with higher non-core education remains at the level of $20 \%$; for about one fifth of employers, it is characteristic that the level of education does not matter at all. The diversity of the economy, which is especially clearly manifested in the regional context, largely determines the very heterogeneous requirements for jobs and the quality of the labor force. Organizations operating in rather conservative spheres of economic activity are rather restrained in their attitude to innovations, therefore, they value experience and qualifications in employees. The level of education is considered here only as, so to speak, a necessary attribute of employment. However, in organizations focused on more modern practices, the requirements for high-quality and specialized education are already very obvious. Moreover, many recruiting agencies ask to indicate in the resume not just the direction of training obtained as a result of specialized education, but also the average score 
for training, participation in various scientific events, places of practice, etc. and in the level of preparedness, and in the personal qualities of employees, reflecting the possible mobility and self-development. In addition, one more interesting tendency was revealed for the studied organizations of Taganrog.

New trends, reflecting the change in the legal framework governing the labor market, are largely becoming the reality of the present day, while being introduced, they also require wide awareness, especially among young people, of these changes. The priority is the progressive and widespread dissemination of professional standards. The reaction of employers, in this sense, is somewhat late, they assess the situation from the point of view of the prevailing conditions and, showing forecasts of future personnel needs, are very restrained, they are guided mainly by the existing standards of employment. However, the opportunities for economic growth will be higher only when a balanced labor market can be achieved considering the realities of the ongoing transformations in the productive forces of society. This requires a solution to the problem associated with the increase in structural unemployment in the regions. It has been updated recently, in particular, due to insufficient coordination in the decision-making process in the labor market of all stakeholders, primarily employers, as well as students in educational institutions of various levels of training, professional educational organizations. In such conditions, one of the ways to solve the problem of harmonizing labor relations, providing the youth labor market with a demanded labor force, focused on training those professional and qualification levels.

The issues of concluding and implementing agreements on social partnership between various organizations are raised in order to conduct, for example, joint research, such as the Labor Market Monitoring of the city of Taganrog, the implementation of socially significant events aimed at harmonizing the interests of the parties to the agreement and focused on obtaining positive externalities in socially, etc. Within the framework of the organization of the youth labor market and effective activities to provide it with a demanded and high-quality labor force, the process of creating information channels, mechanisms of interaction indirectly through the institutionalization of various structures, the functions of which, to one degree or another, are related to vocational guidance, educational or informational activities in work with youth. It is about building a more logical and efficiently functioning relationship of all stakeholders involved in working with youth to one degree or another and in whose tasks this function is included with the help of social partnership. For example, such a relationship can be illustrated using the diagram shown in Figure 3.

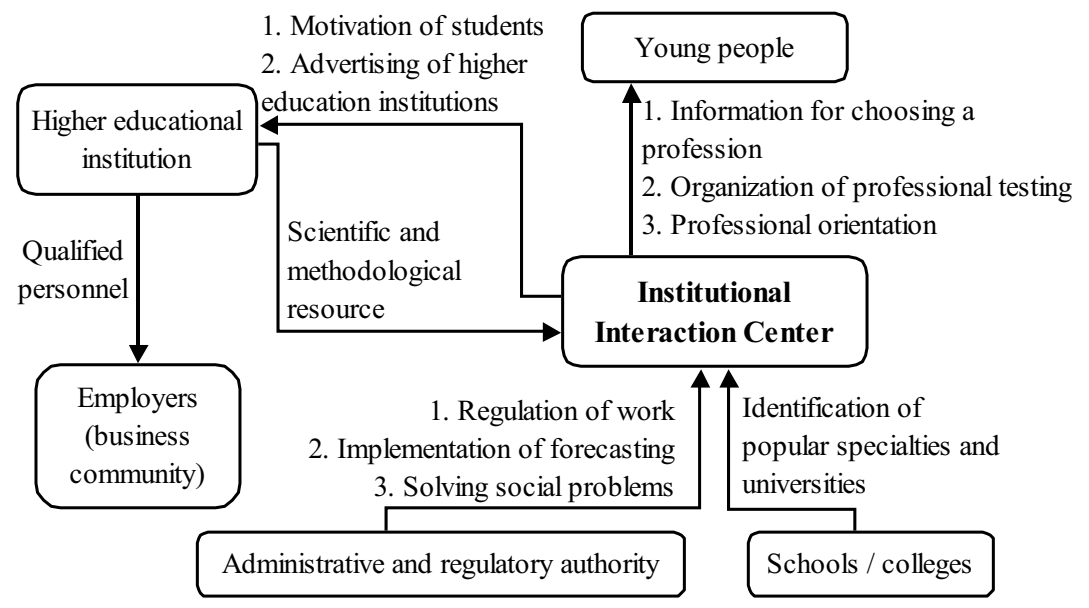

Fig. 3. Scheme of the relationship between the subjects of the labor market in the process of organizing social partnership 
Of course, this approach is very schematic, but it involves an attempt to comprehend the directions and opportunities that social partnership gives to stakeholders in the framework of creating conditions for increasing the efficiency of the labor sphere, in particular with regards to the youth labor market. Thus, the interested parties are employers who are focused on obtaining employees who fully meet the requirements and working conditions, while not many of them are ready to finance the process of training specialists, but act only as a side of the demand, ready to purchase a "labor force" of a certain quality. and for a certain price. In the context of an unstable market environment, a very limited investment potential, especially in the regions, this approach has a very well-reasoned character. However, the issues of the formation of high-quality labor potential cannot but worry any entrepreneur focused on organizing, conducting specialized activities or its diversification. Therefore, the interest in institutionalizing social interaction in the labor market for this category of participants is obvious.

The relationship of employers with specialized educational institutions is implemented on the basis of agreements on the bases of practices, interaction on employment of graduates and, in some cases, retraining and advanced training. The ideal is the state of affairs in which business contracts have been concluded with specialized organizations and educational institutions, which is very problematic to achieve due to many reasons, primarily financial and organizational properties. However, specialized universities, unlike other participants in the market under consideration, act not only as educational, but also as research centers, where knowledge and analytical material is accumulated, the collection and systematization of sectoral features of the development of both the real sector and the relations that are laid in it are collected, including at the level of legal regulation. The exchange of views is very interesting and productive, especially when it comes to the interest in it of certain organizational and managerial structures at the level, for example, of the City Administration or its individual divisions. But such interaction is focused mainly on certain types of actions to regulate the market, carry out specific measures or develop recommendations for achieving a local result. At the same time, the information accumulated, requiring further advancement, mainly does not reach that part of the interested parties that is at the stage of planning on a professional choice, i.e. to youth. Obviously, the question arises of the need to expand the functions of social partnership in the field of career guidance interaction, including, in a broader and more detailed way, the main stakeholder of the process - young people, who are at the stage of professional choice. In the domestic economy, where the requirements for the quality of the labor force and their formalization are subject to active transformation, in accordance with the introduction of the National Qualifications Framework and Professional Standards [5,6], the question of choosing a future profession is transferred to the earliest stages of training future specialists. So, the choice of disciplines for passing the Basic State Exam and Unified State Exam in the graduating classes of secondary schools is already laying the trajectory of the future specialized education. The next step is a professional group, once in which, thanks to specialized education, opportunities for career advancement and growth are associated with the desired profession to a greater or lesser extent. That is, on the basis of professional standards, the priority of specialized education is being consolidated in the labor market, and all personnel strategies are now based exclusively on this approach.

The traditionally established model of vocational guidance, which has existed in our country for a long time, is implemented by general education schools within the framework of a complex of psychological and pedagogical measures related to vocational education, diagnostics of inclinations, the formation of a value attitude to work, interest in various professions, etc. Professional counseling, as a direction of vocational guidance of students, is actualized at the stage of choosing a specialized educational institution, where education will be continued after graduation. Forming a mechanism to ensure a competent and 
qualified professional choice in modern conditions seems to be a priority task, the solution of which can allow achieving the harmonization of the labor market and its segments undergoing significant modernization. At the same time, now the decision-making by individual students about their future profession is often associated not with the inclinations and preferences of a conscious choice, but with a combination of factors, such as the decision of the parents, the image of obtaining one or another education, financial opportunities, social environment, etc. Here we see the possibility of attracting, as an institutional center of interaction, those structures that are focused on working specifically with young people. In their functions, vocational guidance work can be included as one of the non-core activities, but which can coordinate the work on organizing it through social interaction with specialized educational institutions, the Administration and its divisions involved in the analysis and regulation of the labor sphere, etc. Such centers can be, for example, out-of-school work centers, which, along with a variety of realizable goals, highlight the personal development of students, their specialization and self-determination. In addition, examples of interaction are possible through youth library and information centers, whose functions include career guidance within the framework of their responsibilities to attract the interest of young people to topical issues of the modern world through mass events.

Some experience in this matter was formed in the process of testing the model of social interaction on the basis of social partnership agreements concluded between the Municipal Budgetary Institution «Culture Centralized Library System» in Taganrog, a number of general educational and secondary professional organizations and the Taganrog Management and Economics Institute. The specialists of the institute, participating in the Monitoring of the labor market of the city of Taganrog and fully representing the state of its conjuncture, having specialized education and experience in working with young people, are widely involved in conducting thematic, information hours together with the staff of the youth library center in various educational institutions. This is reflected in the planning of their workload in the university and determines the corresponding interest. In addition, the work of specialized circles with students from various educational institutions was organized on the site of the center. Obtaining up-to-date information, qualified assistance in analyzing the current conditions is based on interest and informal communication. Here there is a coordination of competence, activity and problem approaches to training using both group and individual methods. The wide use of play, discussion, training methods is what attracts young people, while the absence of a rigid framework of formalization serves as the basis for interaction focused on a high level of interest. Conducting coordinated mass events attracts interest, both in the work of the youth library center itself, and in urgent problems, the discussion of which takes place with the involvement of professionals of a high level of knowledge and experience, including public speaking and analytical work.

The problems of modernizing human resources in the context of updating innovative processes, significant shifts taking place in the labor market, deepening its segmentation in accordance with professional qualification criteria and improving legal regulation, also require thoughtful measures to influence the qualitative aspects of the labor supply, first of all, on the youth labor market. The educational model of Life Long Learning orients the employee towards the potential and widespread search for areas of improvement, which, apparently, reflects the conditions that characterize the trajectory of the development of society. The emergence of new professional and career incentives [14], the spread of nonstandard forms of employment [15] - these are realities that young people should be ready for when choosing their place in the professional sphere. The traditional model of education and vocational guidance is not able to form the necessary knowledge, skills and abilities to implement a high-quality professional choice and an appropriate set of mobility and growth competencies. In these conditions, the expansion of social interaction with the use of the 
institution of social partnership, which makes it possible to attract a wide range of specialists to the solution of the problem due to the coordination of the interests of various organizations working with youth, can bring this work to a qualitatively new level.

First of all, we can talk about channels for broadcasting information about new trends, the knowledge which is focused on reducing uncertainty in the process of professional choice. But, no less important, the proliferation of institutional centers of interaction of various structures interested in solving one problem, but considering it through the prism of their own interests, can determine breakthroughs in approaches and complexity in decisionmaking. At the same time, the demonstration of the various opportunities provided for the growth and development of young people by the modern world with the condition of their interest in accumulating knowledge, disclosing the sources of this knowledge, analytical potential and readiness to improve it throughout life can be considered as a factor that has a very significant effect on the quality of labor resources. primarily in the context of the youth labor market supply. The educational model used in working with youth is not oriented towards such approaches. Awareness of the need and search for tools for the implementation of social interaction in the creation of mobile, effective and result-oriented social structures that allow using the arsenal of accumulated experience, knowledge and qualifications of various organizational structures can allow, even without attracting additional investment, to improve the conjuncture of the youth labor market. In the context of regional markets, this is all the more relevant, since the issues of high-quality employment of young people, limiting migration outflow and creating conditions for activating economic processes in the regions are the priority tasks of the domestic economy.

\section{References}

1. Yu. R. Tumanyan, O. A. Ishchenko-Padukova, I. V. Movchan, Architectonics of the Creative Potential of the Economy: Imperatives and Sociomarkers (South Federal University Publishing House, 2019).

2. L. V. Baeva, Socio-cultural and philosophical problems of the development of the information society (Publishing house "Astrakhan University", 2019).

3. Howard Rose. The Success Diaries. St. Petersburg: Ibooks, 130 (2014).

4. T. V. Petrenko, A. V. Zimovets, V. V. Koshman, Economics and Entrepreneurship. 8, 353 (2018).

5. Background information: Professional standards. URL: http://www.consultant.ru/document/cons doc LAW 157436/

6. O. F. Batrova, V. I. Blinov, I. A. Voloshina [and others] National qualifications framework of the Russian Federation: Recommendations, (Federal Institute for Education Development, 14, 2008).

7. N. S. Blinova, D. V. Sokolov, Bulletin of the Russian University of Cooperation, 2, 18 (2016).

8. N. V. Klimova, V. A. Mikheeva, Kuban State Agrarian University, 120 (06), 1 (2016).

9. Yu. V. Chelyubeva, Tomsk State University Journal, 11 (79), 59 (2009).

10. T. V. Chernova, T. G. Gilina, T. V. Petrenko, Municipal labor market: theory and practice of research (Taganrog: Publishing house of Private Educational Institution of Higher Education «TMEI» 2018).

11. M. K. Gorshkov, G. A. Klyucharev, Continuing education in the context of modernization (Institute of Sociology of the Russian Academy of Sciences, Center for Sociological Research), 232 (2011).

12. I. Grishin, World Economy and International Relations, 5, 39 (2012). 
13. United Nations

http://docstore.ohchr.org/SelfServices/FilesHandler.ashx?enc=FhOD6sgqgzAhFXD9F \%2FeKaFMm83LbFY75RhkIFGrig\%2B6u8rrdxNjFBYY9INVfAVPcXir\%2BpsMQQ5 RvZxAyvbUKjRwD\%2FjHzz25YTL5Yu37Nd108nEn2BAriE0TGZGTUNvi4 (2021)

14. Dani Rodrik. Economics Rules. - Petersburg: Ibooks, 268 (2015).

15. Non-standard forms of employment. Analysis of problems and prospects for solutions in different countries. Review version. International Labor Office - Geneva: ILO, (2017). 